\title{
SOCIOECONOMIC FACTORS INFLUENCING MARKET PARTICIPATION OF HORTICULTURAL SMALLHOLDER FARMERS IN THE ALFRED NZO DISTRICT, EASTERN CAPE, SOUTH AFRICA
}

\author{
Phokele Maponya $^{1 \bowtie}$, Versity Kekana ${ }^{1,2}$, Grany M. Senyolo${ }^{2}$, Sonja L. Venter ${ }^{1}$ \\ ${ }^{1}$ ARC - Vegetable and Ornamental Plant Institute, South Africa \\ ${ }^{2}$ Tshwane University of Technology, South Africa
}

\begin{abstract}
The purpose of this paper is to identify the socioeconomic factors influencing market participation of horticultural smallholder farmers in the Alfred Nzo district. Cross-sectional data was collected by the Agricultural Research Council and the Department of Rural Development and Land Reform in January 2014 from 48 horticultural smallholder farmers in Alfred Nzo district using a structured questionnaire. Binomial logistic regression analysis was used to analyze the data. The results showed that market participation was influenced by access to market information, type of road and availability of transport to market. The empirical results will be useful for horticulture farmers, marketers and policy makers in developing efficient production and marketing strategies. The government and private sector should establish a model specific to the actual needs of smallholder farmers of the Alfred Nzo district, which should include improvement of roads to farming sites and a wellcoordinated and efficient transporting system which must be designed specifically for smallholder farmers in the district.
\end{abstract}

Keywords: market participation, binary logistic regression, horticultural smallholder farmers, Alfred Nzo District

\section{INTRODUCTION}

Poverty in Africa has been found to be predominantly a rural phenomenon. About 75 percent of the world's poor are believed to work and live in rural areas, and it is estimated that, by 2020, 60 percent of the poor will still be rural (Mathenge et al., 2010). Because agriculture is the major economic activity in rural areas, various interventions were made to capitalize on opportunities offered by the sector to improve the livelihood of rural people. Commercial agriculture is viewed as an effective route for rural development, however it will require some form of transformation out of subsistence production systems to a more profit-driven system. Profit-driven production can be a way to achieve welfare gains through specialization and comparative advantage, economies of scale and regular interaction and exchange of ideas (Mathenge et al., 2010).

Whether smallholder farmers can participate in formal markets depends on their capacity to meet minimum production requirements, both in terms of quantities and product standards; it also requires that expected profits be large enough to encourage farmers to produce. Makhura et al. (2001) alluded that smallholder farmers are unable to participate in the markets because of a range of constraints and barriers reducing incentives for participation. Primary productive inputs and socioeconomic factors were found to be a determinant for market participation for smallholder farmers in the Eastern Province (Jari, 2009 and Maponya et al. 2014). Hazell

\footnotetext{
$\bowtie$ PhD Phokele Maponya, ARC - Vegetable and Ornamental Plant Institute, Private Bag X293, Pretoria, 0001, South Africa, e-mail: maponyap@arc.agric.za; https://orcid.org/0000-0003-4883-2474
} 
Maponya, P., Kekana, V., Senyolo, G. M., Venter, S. L. (2018). Socioeconomic factors influencing market participation of horticultural smallholder farmers in the Alfred Nzo District, Eastern Cape, South Africa. J. Agribus. Rural Dev., 4(50), 421-427. http:// dx.doi.org/10.17306/J.JARD.2018.00421

et al. (2007) indicated that effective market participation is challenged by lack of innovative institutions to support farmers. This is true due to the fact that previous marketing policies have neglected the smallholder farmers in favor of commercial farmers. Van Rooyen et al. (1995) explained that the 1968 Marketing Act excluded other categories of farmers such as smallholder farmers and part-time farmers in favor of commercial farmers. However, the Act was later recalled and substituted by the 1996 Agricultural Product Act which aimed at opening opportunities for all farmers.

The same fate of market exclusion by marketing policies was experienced in other African countries (National..., 2011 and Byron et al., 2014). It was clear that smallholder farmers were since marginalized by agricultural marketing policies and, as a result, they still struggle to penetrate the high-value markets. The same issues are faced by horticultural smallholder farmers in the Alfred Nzo district who are characterized by poor resources such as land, infrastructure and capital (Local government handbook, 2016). Smallholder farmers are increasingly recognized because of their contribution to household food security and job creation for rural communities (Hlongwane et al., 2014). This is true due to the fact that market participation has the potential to stimulate economic growth in rural areas especially if smallholder farmers are supported with relevant resources. The study raises important issues which, when properly addressed, might stimulate smallholder farmers' market participation in the Alfred Nzo district. Proper interventions and development strategies require knowledge of clientele base's needs. The results of the study could serve as a benchmark for follow-up studies in the district and could also be used as an input for agricultural development strategies in the district to encourage smallholder farmers to participate in high-value markets.

The study focused on market participation behavior of horticultural smallholder farmers in Alfred Nzo district, in order to identify specific intervention measures that would interest the farmers. The study attempted to determine the socioeconomic factors influencing farmers' decision to use or not to use formal markets. The findings of the study will serve as a foundation for policy makers and developmental agencies such as the Agricultural Research Council (ARC) and the Department of Rural Development and Land Reform (DRDLR), the custodian of the Agri-parks program. The Agri-park program is a government intervention measure taken in response to constrains hampering smallholder farmers to upgrade into commercial production systems. The primary aim of the program was to establish rural horticultural markets in support of smallholder farmers in 44 of poorest districts within the provinces of South Africa. Thus, smallholder farming has an important role in transforming agriculture in the districts from subsistence to market-oriented production. As indicated by other authors, commercialization of agriculture can be achieved by promoting value addition to high-valued agricultural commodities, particularly horticultural products, as a way to support the agribusinesses and link farmers with markets (Osmani and Hossain 2015).

\section{MATERIAL AND METHODS}

\section{Study area}

Alfred Nzo district is located on the north-eastern side of the Eastern Cape province. Stretching from the Drakensberg mountains, it borders Lesotho in the north, Harry Gwala district in the east and O.R. Tambo District in the south. Alfred Nzo district consists of four local municipalities, namely Mbizana, Ntabankulu, Umzimvubu and Matatiele (Alfred Nzo District, 2014). The average minimum temperature ranges from $7^{\circ} \mathrm{C}$ to $10^{\circ} \mathrm{C}$ in winter from $18^{\circ} \mathrm{C}$ to $24^{\circ} \mathrm{C}$ in summer. A case study by Harpe (2003) highlighted that rainfall season in the district occurs in summer, from October to March, although approximately $30 \%$ of the annual rainfall occurs in the winter months. The study further explained that average annual rainfall ranged from between $1000 \mathrm{~mm}$

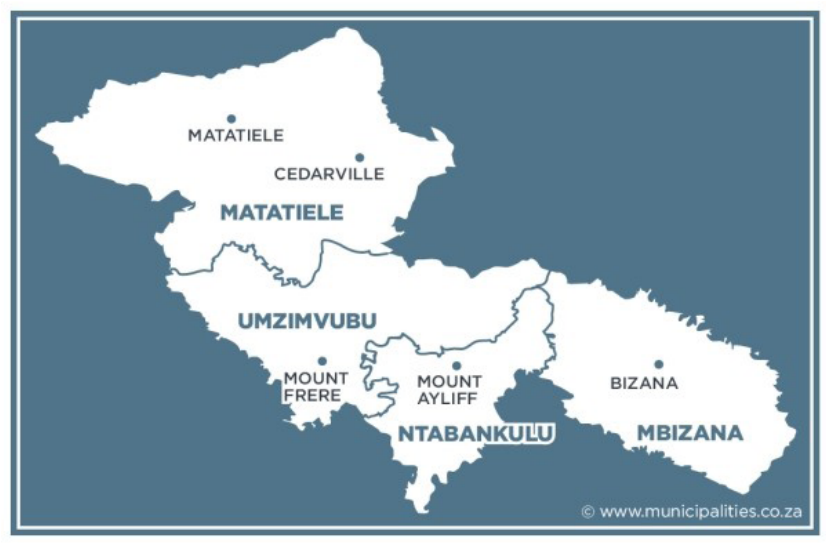

Fig. 1. Alfred Nzo District Map

Source: The Local Government Handbook, 2016 

cultural smallholder farmers in the Alfred Nzo District, Eastern Cape, South Africa. J. Agribus. Rural Dev., 4(50), 421-427. http:// dx.doi.org/10.17306/J.JARD.2018.00421

and $1400 \mathrm{~mm}$ along the coast to approximately $700 \mathrm{~mm}$ to the north, which made Alfred Nzo district one the most reliable rainfall zones in South Africa.

\section{Data and empirical model used}

The study used secondary data (cross-sectional information) collected during a skill audit conducted by ARC and the DRDLR in the Alfred Nzo district in 2014. The Alfred Nzo district Department of Agriculture's database was used to source 48 horticultural projects. The ARC only intended to work with horticultural projects which were operational. Therefore, a project database verification was conducted between ARC and Alfred Nzo Department of Agriculture officials to identify operational horticultural projects.

Binomial logistic regression was used to analyze the farmers' decisions to participate in formal or informal markets and the factors that influenced these choices. According to Tustin and Van Wyk (2005), a typical logistic regression model which was used is as follows:

$$
\begin{aligned}
& \operatorname{Logit}\left(P_{i}\right)=\ln \left(P_{i} / 1-P_{i}\right)= \\
& =\alpha+\beta_{1} X_{1}+\ldots+\beta_{n} X_{n}+U_{t}
\end{aligned}
$$

Where:

$\ln \left(P_{i} / 1-P_{i}\right)$ : logit for market participation choices

$P_{i}$ : not participating in markets

$1-P_{i}$ : participating in markets

$\beta$ : coefficient

$X$ : covariates

$U_{i}$ : error term

In the model, the choice of market channel was represented by the dependent variable; participating in the informal market channel had been set as the reference category. The choice of market channel described the decision to sell the produce through a formal market channel or an informal market channel. It followed that $P_{i}$ represented the probability of participating in the formal market channel while $\left(1-P_{i}\right)$ was the probability of participating in the informal market channel. In other words, the model was used to assess the odds of selling produce through a formal market channel against selling produce through an informal market channel. The binomial logistic regression model is useful in analyzing data where the researcher is interested in finding the likelihood of a certain event. In other words, based on data from relevant independent variables, binomial logistic regression is used to predict the probability (p) of the occurrence of an event while not necessarily getting a numerical value for the dependent variable (Gujarati, 1992). According to another explanation by Tustin and Van Wyk (2005), binary logistic is useful when the research has one dichotomous dependent variable (which means there are two categories to be predicted).

\section{RESULTS AND DISCUSSION}

In this section, descriptive statistics of the variables and the estimation results of the binomial regression model are presented. The results will help identifying the factors that influence smallholder farmers to participate in the formal market to sell their horticultural crops.

\section{Descriptive statistics of the variables}

Description and descriptive statistics of the variables used in the analysis are reported in Table 1. The results show that only 35 percent of horticultural smallholder farmers of Alfred Nzo were using formal market. Usually, age is used to determine the future of any sector; fifteen percent of project leaders were generally 1835 years old. Regarding gender of the project leader, the results indicated that 43.8 percent were male. About 33.3 percent of project leaders had secondary education. Farmers who had achieved tertiary education are expected to interpret and understand market information better than those at a lower education level. The lower educational levels among the sampled projects implies that written market information might be of minimal benefit to such farmers. This indicated that there were more farmers who still struggle to read and understand written market information.

It is evident in Table 1 that most smallholder farmers in Alfred Nzo district do not have title deeds. The results showed that 10 percent of farmers in Alfred Nzo district use own land. Seventy-seven percent of the projects occupy land between 1-5 ha. The results revealed that only 15 percent of projects had less than five beneficiaries per project. The results are in line with the DRDLR guideline to support cooperative projects that require a minimum of five members to register.

The results showed that in average, projects beneficiaries travel a distance of 30 kilometers to formal markets. However, the results furthermore indicated that some farmers are not exposed to long distance to market their produce, as indicated by the minimum distance of zero kilometers. Some project leaders reported to be 
Maponya, P., Kekana, V., Senyolo, G. M., Venter, S. L. (2018). Socioeconomic factors influencing market participation of horticultural smallholder farmers in the Alfred Nzo District, Eastern Cape, South Africa. J. Agribus. Rural Dev., 4(50), 421-427. http:// dx.doi.org/10.17306/J.JARD.2018.00421

Table 1. Description and descriptive statistics of variables used in the study

\begin{tabular}{llc}
\hline \multicolumn{2}{c}{ Variable } & \multicolumn{2}{c}{ Description of variables } & Percentage \\
\hline Dependent variable & 35 \\
\hline MARPART & 1 if project uses formal market, 0 otherwise & 15 \\
\hline Independent variable & 43.8 \\
\hline AGE & 1 if age of the project leader is $18-35$ years, 0 otherwise & 33.3 \\
GEND & 1 if female, 0 otherwise & 10 \\
EDL & 1 if the project leader has secondary education, 0 otherwise & 77 \\
LNDAQ & 1 if own land, 0 otherwise & 33.3 \\
LASIZ & 1 if the area of land is $1-5$ hectares, 0 otherwise & $30 \mathrm{~km}$ \\
NUMBEN & 1 if number of members per project is $0-5,0$ otherwise & 12.5 \\
DSTMARK & Distance to the market & 13 \\
TRAMARK & 1 if the project uses own transport, 0 otherwise & 4.2 \\
TYPROA & 1 if the project uses tarred road, 0 otherwise & 31.3 \\
PROCON & 1 if the project has a production contract, 0 otherwise & 35 \\
MARINF & 1 if the project has access to market information, 0 otherwise \\
ACCFUD & 1 if the project has access to funding, 0 otherwise & \\
\hline
\end{tabular}

Source: survey data, 2014.

using farm gate trading methods which eliminated the challenges associated with distance. These results were supported by the replies of the farmers who claimed to sell their produce around their villages and to some customers from local towns who come to collect the produce at farm gate. The availability of reliable transport is one of the key factors for a smooth operation of farming enterprises. The results showed that 12.5 percent of projects used their own transport. This scenario revealed that almost the entire population of smallholder farmers in the Alfred Nzo district do not own the transport they use to ferry produce to marketing places. In addition, thirteen percent of horticultural farmers in Alfred Nzo district used a tarred road to the market. As explained by some of the farmers, certain roads were impassable during the rainy season, especially the gravel roads. This clearly showed that the marketing of produce outside the communities will be difficult because of poor road infrastructure.

The availability of market information increases confidence of willing project leaders to market their produce. In other words, market information allows farmers to make informed decisions. Regarding access to market information, 31.3 percent of the projects had access to market information. This result implies that smallholder farmers of Alfred Nzo are very limited in terms of market information. However, 4.2 percent of the projects had access to production contracts. These results imply that most farmers are faced with the risk of losing their produce at the harvesting stage since there is no certainty as to a fixed quantity of produce to be sold or marketed. In addition, 35 percent of horticultural projects in the Alfred Nzo district had access to funding.

\section{Factors influencing smallholder farmers' market participation}

Several demographic and socioeconomic variables, which are believed to have an influence on the decision to participate in the market, were included in the binomial logistic regression model. The estimation model results are presented in Table 2. Logistic Regression was found to reasonably (76.9 percent) fit the pseudo R-squared. This makes the model modestly good when 
Maponya, P., Kekana, V., Senyolo, G. M., Venter, S. L. (2018). Socioeconomic factors influencing market participation of horticultural smallholder farmers in the Alfred Nzo District, Eastern Cape, South Africa. J. Agribus. Rural Dev., 4(50), 421-427. http:// dx.doi.org/10.17306/J.JARD.2018.00421

Table 2. Binomial logistic results for formal market participation

\begin{tabular}{|c|c|c|c|c|}
\hline & Coefficient (B) & Wald & Sig. & $\operatorname{Exp}(B)$ \\
\hline AGE & .004 & .005 & .941 & 1.004 \\
\hline GEND & .442 & .091 & .763 & 1.555 \\
\hline EDL & -2.742 & 2.089 & .148 & .064 \\
\hline LNDAQ & .098 & .003 & .953 & 1.103 \\
\hline LASIZ & -.144 & .251 & .616 & .866 \\
\hline NUMBEN & .065 & .942 & .332 & 1.067 \\
\hline DSTMARK & -.065 & 2.702 & .100 & .937 \\
\hline TRAMARK & $11.639 *$ & 3.282 & .070 & 113470.219 \\
\hline TYPROA & $5.436^{* *}$ & 4.976 & .026 & 229.543 \\
\hline PROCON & 22.970 & .000 & .999 & 9453532476.034 \\
\hline MARINF & $-3.549 *$ & 3.604 & .058 & .029 \\
\hline ACCFUD & -.348 & .057 & .811 & .706 \\
\hline Constant & -26.754 & .000 & .999 & .000 \\
\hline \multicolumn{5}{|c|}{ Model summary } \\
\hline Step & -2 Log likelihood & Cox and Snell R-Squared & \multicolumn{2}{|c|}{ Nagelkerke R-Squared } \\
\hline 1 & $23.026 \mathrm{a}$ & .560 & \multicolumn{2}{|c|}{.769} \\
\hline
\end{tabular}

* Significant at a $10 \%$ level of probability. ** Significant at a $5 \%$ level of probability.

Source: survey data, 2014

considering the intricacy of research objectives and the abundant factors that influence the horticultural projects' decision to participate in the formal market. Three out of twelve variables listed in the model exhibit the expected effects on the horticultural projects' decision to participate in the formal market. Of the three significant variables, two were positively significant to the study while one was found to be negatively significant.

The logistic estimation result revealed that the "transport to market" variable is statistically significant at 10 percent and has a positive influence on the projects' decision on market participation. These results imply that having a personal means of transportation increases the probability for the project to sell horticultural produce at the formal market. These results are supported by Gabre-Madhin (2001) and Maponya et al. (2015) who stated that transport availability had a positive influence on smallholder market participation, especially if they are located away from the formal market. This is expected, since farmers with personal transportation prefer to take their produce to the formal market where they may obtain a better price through bargaining. Moreover, projects with their own means of transport were likely to transport their agricultural produce on time to the market.

The coefficient for the type of road to the nearest town was found to be positive and significant at a $5 \%$ level of probability. These results imply that the use of tarred road to the nearest town increases the probability for the project to sell horticultural produce at the formal market. This is expected, since farmers with access to good roads were positively influenced to participate due to its effects on reducing transaction costs. The results concurred with Jari (2009) and Senyolo et al. (2009) who revealed that poor conditions of roads, which are often impassable during the rainy season, had an adverse effect on the transportation of the produce to, and on the accessibility of, local output markets. The type of road from the farm to market locations plays a pivotal role to highly perishable crops as they are sensitive to bruising 
Maponya, P., Kekana, V., Senyolo, G. M., Venter, S. L. (2018). Socioeconomic factors influencing market participation of horticultural smallholder farmers in the Alfred Nzo District, Eastern Cape, South Africa. J. Agribus. Rural Dev., 4(50), 421-427. http:// dx.doi.org/10.17306/J.JARD.2018.00421

and squashing which might compromise quality and hence affect the farmer's price.

The "access to market information" variable was found to be negatively significant at $10 \%$. This implies that the willingness to participate in formal markets declined with improved access to market information. This is especially true in rural areas where farmers cannot interpret the information correctly to participate in the market. Hence, organizations such as the Agricultural Research Council are actively involved in farmer trainings and technology transfer to enable market participation.

Contrary to earlier expectations, gender, age, education level, land acquisition, land size, access to funding, production contract, distance to market and number of beneficiaries were found to be variables with no significant impact on the farmers' decision to access formal horticultural markets in the Alfred Nzo district.

\section{CONCLUSION AND RECOMMENDATIONS}

The main objective of this study was to identify and assess the socioeconomic factors influencing market participation behaviors amongst smallholder farmers in the Alfred Nzo district. The results of this study suggest that in order for horticultural farmers to increase their access to formal markets, factors such as transport system, market information and road infrastructure have to be improved. This will enable increasing the smallholder farmers' participation in high-value markets. Thus, most smallholder farmers in the Alfred Nzo district were under-resourced and still into subsistence farming. They would go to market only to sell the excess after keeping enough products for household consumption. Considering the constraints and effective factors, the study recommends that efforts be made to upgrade the roads and support the establishment of more points of sales in farming areas in order to reduce transportation costs and thus promote market participation. The government, with help from private sector, should develop suitable models that incorporate smallholder farmers into high-value markets, as it is the case for the Agricultural Research Council and Department of Rural Development and Land Reform Agri-parks Program which aims to build rural agricultural markets. The Johannesburg and Pretoria Fresh Produce Markets are some of the example markets which work with a number of smallholder farmers from different areas. However, the distance from Eastern Cape Province rural areas to Johannesburg make it financially impossible for farmers to ferry their produce.

\section{ACKNOWLEDGEMENTS}

The authors wish to acknowledge the Department of Rural Development and Land Reform for funding. The following Departments/Research Institutes/Local Municipalities are acknowledged: Eastern Cape Department of Agriculture; Alfred Nzo District; Alfred Nzo Local Municipalities; Alfred Nzo Local Farmers; Alfred Nzo Local Economic Development Agencies, Tshwane University of Technology and Agricultural Research Council.

\section{REFERENCES}

Byron, Z., Nelson, M., Kefasi N., Shephard S. (2014). Determinants of soybean market participation by smallholder farmers in Zimbabwe. J. Dev. Agric., 6(2), 49-58.

Gabre-Madhin, E. (2001). Understanding how markets work: transaction costs and institutions in the Ethiopian grain market. IFPRI Research Report. International Food Policy Research, Washington DC.

Gujarati, D. (1992). Essentials of Econometrics. New York: MacGraw-Hill.

Harpe, J. (2003). Scaling up community management in South Africa: The Alfred Nzo District Municipality Case Study.

Hazell, P. C., Poulton, S. W., Dorward, A. (2007). The future of small farms for poverty reduction and growth, Washington D.C: International Food Policy Research 2020 Discussion Paper 42, May 2007.

Hlongwane, J. J., Ledwaba, L. J., Belete, A. (2014). Analysing the factors affecting the market participation of maize farmers: A case study of small-scale farmers in greater Giyani local municipality of the Mopani district Limpopo province. Afr. J. Agric. Res., 9(10), 895-899.

Jari, B. (2009). Institutional and technical factors influencing agricultural marketing channels choices amongst smallholder and emerging farmers in the Kat River. MSc. thesis, Alice, University of Fort Hare.

Makhura, M., Kirsten, J., Delgado, C. (2001). Transaction costs and smallholder participation in the maize market in the Northern Province of South Africa. Seventh Eastern and Southern Africa Regional Maize Conference, 11-15 February. Pretoria.

Maponya, P. I., Modise, D., Van Den Heever, E., Mahlangu, S., Baloyi, N., Maluleke, A., Chauke, A., Mkhari, R., Carstens, J., Van Der Walt, M., Sole, L., Duba, M., 
Maponya, P., Kekana, V., Senyolo, G. M., Venter, S. L. (2018). Socioeconomic factors influencing market participation of horticultural smallholder farmers in the Alfred Nzo District, Eastern Cape, South Africa. J. Agribus. Rural Dev., 4(50), 421-427. http:// dx.doi.org/10.17306/J.JARD.2018.00421

Malebana, J., Mphahlele, I. (2014). The establishment of vegetable and fruit markets and nurseries: A case study in the Waterberg district, Limpopo Province, South Africa. J. Agric. Sci., 6(7), 38-47.

Maponya, P., Venter, S. L., Modise, D., Van Den Heever, E., Kekana, V., Ngqandu, A., Ntanjana, N., Pefile, A. (2015). Determinants of Agricultural Market Participation in the Sarah Baartman District, Eastern Cape of South Africa. J. Human Ecol., 50(1), 1-9.

Mathenge, M., Place, F., Olwande, J., Mithoefer, D. (2010). Participation in agricultural markets among the poor and marginalized: Analysis of factors influencing participation and impacts on income and poverty in Kenya Study Report, Kenya: Tegemeo Institute of Agricultural Policy and Development.

Moloi, J. M. (2008). A comparison of socio economic characteristics that determine the farm income of emerging livestock and emerging farmers in South Africa. M.Sc. dissertation, Turfloop, University of Limpopo.

National Agricultural Marketing Board (2011). Annual report, 2009. Manzini, Swaziland.
Osmani, A. G., Hossain, E. (2015). Market participation decision of smallholder farmers and its determinants in Bangladesh. Econ. Agric., 1(62), 163-179.

Senyolo, G. M., Chaminuka, P., Makhura, M. N., Belete, A. (2009). Patterns of access and utilization of output markets by emerging farmers in South Africa: Factor analysis approach. Afr. J. Agric. Res., 4(3), 208-214.

The local government handbook (2016). A complete guide to municipalities in South Africa. Retrieved May $8^{\text {th }} 2016$ from: http://www.localgovernment.co.za/districts/view/1/ Alfred-Nzo-District-Municipality\#map

Tustin, L. M., Van Wyk, H. (2005). Marketing research in practice. Pretoria: Unisa Press.

Van Rooyen, C. J., Kirsten, J. F., Van Zyl, J., Vink, N. (1995). Structural adjustment, policy reform and agricultural performance in South Africa. Working Paper 15: USAID Southern African Trade and Structural Adjustment Project, Pretoria. 